\title{
E quando as bichas, sapatão, travas e trans caminham pelas ruas? Os emblemas sociais da caminhabilidade no Brasil
}

\author{
Antoniel dos Santos Gomes Filho \\ Antônio Ailton de Sousa Lima ${ }^{2}$ \\ Antônio Micael Pontes da Silva ${ }^{3}$ \\ Larissa Ferreira Nunes ${ }^{4}$ \\ Tadeu Lucas de Lavor Filho 5 \\ Recebido em setembro de 2020 \\ Aceito em dezembro de 2020
}

\section{RESUMO}

As práticas de violência contra as populações dissidentes de gênero e sexualidade são uma realidade cotidiana em todo o território brasileiro, marcada pela apreensão, sofrimento, insegurança e medo. Tal realidade social se expressa por estatísticas através dos relatórios que dizem respeito a práticas de violência voltadas ao público LGBTs. A questão da violência suscita uma interlocução com outros temas, tais como da mobilidade urbana que envolve o caminhar, explorando territórios, experiências e vivências. Nesse percurso, o estudo objetiva realizar uma reflexão sobre a caminhabilidade de pessoas dissidentes de gênero e sexualidade, com foco no público LGBTs, em seu entrelaçamento com a violência. Metodologicamente busca-se uma ampliação e maiores discussões a partir do campo socioantropológico da Teoria da Caminhabilidade, e assim, caracteriza-se por uma revisão de literatura em torno de uma hermenêutica problematizadora na qual faremos a confluência em teorias e conceitos. Com isso

\footnotetext{
${ }^{1}$ Mestre em Educação pela Universidade Federal do Ceará (UFC). Professor do curso de Psicologia do Centro Universitário Vale do Salgado (UniVS) e da Faculdade de Ciências Humanas do Sertão Central (FACHUSC). Discente de Licenciatura em Sociologia pela UNIFAVENI. E-mail: antoniel.historiacomparada@gmail.com. ORCID: https://orcid.org/oooo-ooo3-2230-4315.

${ }^{2}$ Mestrando em Psicologia na Universidade Federal do Ceará- UFC (Bolsista CAPES). Licenciado em Sociologia, Bacharel em Humanidades e Especialista em Gestão Pública Municipal na Universidade da Integração Internacional da Lusofonia Afro-Brasileira (UNILAB). Pesquisador e colaborador na Rede de Estudos e Afrontamentos as Pobrezas, Discriminações e Resistências (ReaPODERE/UNILAB-UFC). Email: ailton_lima12@hotmail.com. ORCID: https://orcid.org/oooo-ooo2-5696-2255.

${ }^{3}$ Mestrando em Sociologia na Universidade Federal do Ceará (UFC). Licenciado em Sociologia e Bacharel em Humanidades na Universidade da Integração Internacional da Lusofonia Afro-Brasileira (UNILAB). Membro do Grupo de Pesquisa e Extensão em Segurança Pública, Justiça e Direitos Humanos (SEJUDH/UNILAB). E-mail: micaelpontessilva@alu.ufc.br. ORCID: https://orcid.org/oooo-ooo3-0997$391 X$.

${ }^{4}$ Doutoranda e Mestre em Psicologia na Universidade Federal do Ceará - UFC - (Bolsista FUNCAP-CE), Fortaleza-CE, Brasil. Especialista em Saúde Mental pela Universidade Estadual do Ceará (UECE). Integrante do Grupo de Pesquisa e Intervenções sobre Violências, Exclusão Social e Subjetivação (VIESES/UFC). E-mail: larissafnpsico@gmail.com. ORCID: https://orcid.org/oooo-ooo1-5384-o896.

5 Doutorando e Mestre em Psicologia. Universidade Federal do Ceará - UFC (Bolsista FUNCAP-CE), Fortaleza-CE, Brasil. Especialista em Docência do Ensino Superior e Tutoria de Educação à Distância (IPEMIG). Pós-graduando Latu Sensu em Gênero, Diversidade e Direitos Humanos (UNILAB). Colaborador do Laboratório em Psicologia, Subjetividade e Sociedade (LAPSUS). Extensionista no Projeto É da Nossa Escola que falamos (UFC). Membro do Corpo Editorial da Revista África e Africanidades. E-mail: tadeulucaslf@gmail.com. ORCID: https://orcid.org/oooo-ooo3-2687-1894.
} 
esperamos estabelecer maiores compreensões sobre os/as dissidentes sexuais e de gênero e as situações de vulnerabilidades em suas caminhadas nas cidades.

Palavras-chave: Gênero; Sexualidade; Violência; Caminhabilidade.

\title{
And when gay, truck drivers, locks and trans walk the streets? the social emblems of walkability in Brazil
}

\begin{abstract}
The practices of violence against dissident populations of gender and sexuality are a daily reality throughout the Brazilian territory, marked by apprehension, suffering and fear of being victims. This reality is expressed by statistics through reports that refer to violence practices aimed at the LGBTs public. The issue of violence raises an interlocution with other themes, such as urban mobility that involves walking, seeking to explore territories and their experiences. This study aims to reflect on the Walkability and gender issues in Brazil, focusing on gender and gender dissident people and populations. In this sense, methodologically looking for an expansion and greater discussions from the socio-anthropological field of the Theory of Walkability, the present study is characterized by a literature review in which we will make the confluence in theories and concepts. With this we hope to establish greater understandings about sexual and gender dissidents and the situations of vulnerabilities in their walks through the cities.
\end{abstract}

Keywords: Gender; Sexuality; Violence; Walkability.

\section{Et quand des homosexuels, des camionneurs, des cadenas et des trans marchent dans les rues? les emblèmes sociaux de la marchabilité au Brésil}

\section{RÉSUMÉ}

Les pratiques de violence contre les populations dissidentes de genre et de sexualité sont une réalité quotidienne sur tout le territoire brésilien, marquée par l'appréhension, la souffrance, l'insécurité et la peur. Cette réalité sociale est exprimée par des statistiques à travers des rapports faisant référence à des pratiques de violence à l'encontre du public LGBTs. La question de la violence soulève une interlocution avec d'autres thèmes, comme la mobilité urbaine qui implique la marche, l'exploration de territoires, d'expériences et d'expériences. Dans cette voie, l'étude vise à réfléchir sur la marchabilité des personnes dissidentes de genre et de sexualité, en se concentrant sur le public LGBTs, dans leur entrelacement avec la violence. Méthodologiquement, une expansion et des discussions plus approfondies sont recherchées dans le champ socio-anthropologique de la théorie de la marche, et ainsi, elle se caractérise par une revue de la littérature autour d'une herméneutique problématique dans laquelle nous ferons la confluence des théories et des concepts. Avec cela, nous espérons établir une meilleure compréhension des dissidents sexuels et de genre et des situations de vulnérabilité lors de leurs promenades dans les villes.

Mots clés: Genre; Sexualité; La violence; Walkability.

$\mathrm{E}_{\mathrm{ste}}$ artigo tem como campo de problematização os aspectos da violência contra dissidentes de gênero e sexualidade ${ }^{6}$ e que também perpassa os direitos à cidade

\footnotetext{
${ }^{6}$ Elegemos a noção de dissidência sexual e de gênero ao invés de diversidade sexual e de gênero, como tentativa de reiterar o caráter subversivo e de fugir das capturas políticas, masculinista e normalização
} 
(AGIER, 2015). Desse modo, trazemos alguns apontamentos sobre o conceito de caminhabilidade7 $^{7}$ SPECK, 2016) e sua restrição diante dos casos de violência urbana. Sobretudo as pessoas que são marcadas interseccionalmente por opressões e representações sociais que corroboram para intensificação das múltiplas formas da violência.

Para pensar as representações sociais no Brasil e as concepções geradas em torno destas, faz-nos necessário questionar sua "naturalização" a partir de uma construção histórica que se deu mediante a três grandes estruturas sociais: o colonialismo, o patriarcado e o capitalismo (SANTOS, 2019). Concebemos que, a partir dessas estruturas surgem novas subestruturas que operam como práticas de opressão, exploração e extermínio em torno de pessoas que não obtém determinados privilégios sociais por não seguirem as normas hegemônicas vigentes, ou por não estarem em consonância com o padrão estabelecido por estas estruturas, de modo a subalternizar todos/as que não são homens, brancos, héteros e burgueses (LUGONES, 2014).

Assim, apontamos algumas representações disseminadas sobre o Brasil, como por exemplo, a suposição alegórica do país da "liberdade", inclusive sexual (CARNEIRO, 2011), e também de alegorias folclóricas, orgiásticas, receptivas e festivas, formulando um imaginário social racializado, generalizado e classista (NUNES, 2020). Outro ideal que figura tal imaginário social são idealizações em torno da mulher, sobretudo quando são mulheres negras, onde o racismo forja uma dupla representação: 1) a hiperssexualização da mulher negra, cuja imagem remonta um convite e recepção para o turista estrangeiro, ou até mesmo para brasileiros/as que enquadra tipos de mulheres para transar e casar; 2) assexualiza, retirando a conotação sexual, especificamente na figura da "mãe preta" (GONZÁLEZ, 1984).

Connell (2014), pontua de modo mais amplo que outras divisões, além do gênero, estruturam a sociedade ocidental moderna, a saber raça e classe. Portanto, quando se entrecruzam o racismo ao sexismo, e também questões territoriais de cada

em torno do termo diversidade. De maneira semelhante, também não utilizamos o termo queer por este não ter o mesmo teor político que representa nos países norte-americanos (COLLING, 2015).

${ }^{7}$ Entendemos a caminhabilidade como uma prática social produzida que permite ou obstaculiza o direito de caminhar, ou seja, de ir e vir na cidade, e sobretudo, de ocupar a via pública das ruas, e cuja intervenção se aplica de diferentes formas nos corpos da cidade. 
região, pessoas dissidentes se encontram em condição de maior vulnerabilização e passíveis a violências, especificamente a LGBTfobia (GRUPO GAY DA BAHIA, 2020; PERES; SOARES; DIAS, 2020).

Caminhar na maioria dos centros urbanos brasileiros talvez não seja uma experiência "segura", dado que a violência urbana que permeia a vida cotidiana tem afetado, historicamente determinados grupos sociais (CERQUEIRA et al., 2020). Conforme aponta Nascimento, Lucena e Gomes Filho (2016), o espaço urbano, em especial a rua, cria fronteiras simbólicas, que são atravessadas por contextos econômicos, envolvendo aqueles que ocupam um espaço num jogo relacional (físico e simbólico) que se materializa desde a contratação de segurança privada, até a organização dos corpos.

Logo, a heterogeneidade que configura o espaço urbano torna-se excludente, em específico para os sujeitos que habitam as periferias do capitalismo (BARROS et al., 2019). E nesse lugar da rua segura (a rua abastada) aqueles que são dissidentes às normas, e que não trazem consigo o poderio econômico como pressuposto base de aceitação, são colocados no lugar do inseguro, daquele que não se pode confiar, daquele que abala a ordem de segurança. Assim, o corpo que era para ser alvo de proteção, torna-se o símbolo da insegurança e também simbólico desse “sujeito abastado”.

De modo a exemplificar, alguns dados brasileiros são importantes de serem apresentados para uma melhor compreensão. De acordo com a Rede Trans Brasil, publicado pela ONG Transgender Europe (2017), nos últimos oito anos 868 travestis e transexuais foram assassinadas. Em 2019, a cada 26 horas uma pessoa LGBTs foi assassinada no país, totalizando 329 vidas interrompidas por serem pessoas dissidentes sexuais e de gênero (GRUPO GAY DA BAHIA, 2020).

Esses dados podem ser maiores, posto que é crescente a subnotificação e a invisibilidade que se dá aos crimes de homofobia, tanto pela falta de aparato técnico, quanto pelo preparo por parte dos agentes de segurança em lidar com essas situações do modo a colocarem como homicídio e não relacionarem com a homofobia. Outro vetor são os atravessamentos pelo machismo que a "cisgeneridade" (VERGUEIRO, 2015) ou o sistema “cisheteropatriarcal” (AKOTIRENE, 2018) estruturam as relações de poder-saber e subjetivação, inclusive no âmbito da justiça. 
Desse modo, caminhar pelas ruas brasileiras envolve uma série de fatores, desde os que vão do planejamento urbano e da infraestrutura, até os aspectos de ordem social e cultural. Nesse sentido, realiza-se uma reflexão sobre a Teoria Geral da Caminhabilidade, com base nas concepções do urbanista norte-americano Jeff Speck (2016) e as questões de gênero no Brasil, principalmente no que tange a interseccionalidade (GONZÁLEZ, 1984; LIMA, 2018; RIBEIRO, 2018), em especial relacionado à violência urbana contra as pessoas e grupos dissidentes sexuais e de gênero (TREVISAN, 2018; MELO, 2018; PRADO; MACHADO, 2012). Busca-se um processo dialógico entre a teoria apresentada, e uma ampliação no campo socioantropológico, uma vez que compreendemos que os/as dissidentes sexuais e de gênero encontram-se em maior vulnerabilidade em suas caminhadas pelas/na cidades.

Temos como objetivo refletir sobre a caminhabilidade e seu entrelaçamento com a violência urbana. Faz-se o uso de uma metodologia qualitativa com base em uma revisão bibliográfica e de cunho hermenêutico (GAMSON, 2006; GIL, 2009). Ressaltamos que o estudo se debulha a partir da Teoria Geral da Caminhabilidade (SPECK, 2016), na qual se apresenta uma discussão geral, e como esta reflete uma condição de caminhada segura no espaço urbano. Ademais, no presente estudo, apresentamos sob o prisma interseccional uma discussão sobre as violências sofridas no território por aqueles/as que não seguem os padrões estabelecidos para os gêneros e as sexualidades construídas histórica e socialmente no Brasil. Por último, apresentamos as considerações finais, pontuando algumas conclusões iniciais sobre o tema, bem como indagações que podem ser alvo de novos estudos.

\section{Esboços da caminhabilidade: por onde caminhamos?}

A Teoria Geral da Caminhabilidade - TGC (SPECK, 2016) é elaborada a partir do contexto norte-americano na qual consiste em trazer as condições e as interferências no ato de caminhar pelas cidades. Oriundo do urbanismo, o conceito consiste em discutir sobre desenhos urbanos que configuram a rede de caminhos e deslocamentos entre os sujeitos. Desse modo, o presente artigo propõe em realizar um diálogo entre a TGC e as realidades brasileiras no que diz respeito às questões de gênero e sexualidade, assim 
vislumbrando novos olhares e transbordamentos de pensamento a partir do campo socioantropológico.

Speck (2016) descreve que a caminhabilidade se estabelece a partir de compensações físicas e sociais do caminhar, pois esta contribui para a vitalidade e experiência urbana. Relacionado à arquitetura e ao urbanismo das cidades, temos a compreensão que o conceito em estudo deve ultrapassar os aspectos técnicos que envolvem planejamento e estrutura urbana. Assim, entendemos a caminhabilidade como uma prática social que deve ser compreendida a partir de aspectos sociais e culturais, sendo os mesmos problematizados e questionados.

Nesse sentido, entende-se que as cidades são para além de prédios, construções arquitetônicas e outras estruturas. A cidade é um locus abstrato, simbólico, múltiplo e complexo. É “[...] um campo de interação em que as pessoas se encontram, criam novos laços, tratam das diferenças, alimentam, em suma, redes de sociabilidade numa paisagem aparentemente desprovida de sentido ou lida apenas na chave da pobreza ou exclusão" (MAGNANI, 2003, p 86).

Assim, compreende-se a cidade como um espaço de interação, transação e de caminhabilidade. Ou seja, se estabelece uma relação do social no espacial, no que diz respeito ao uso da sociedade em espaços diversos. Magnini (2003) discorre que por meio do campo da antropologia urbana é possível pensar os usos dos espaços, os comportamentos e suas regularidades. A exemplo disso, é necessário pontuar que os indivíduos ou agentes sociais “[...] não estão dispersos ou submersos no caos urbano, mas se apropriam de forma distinta buscando experiências, reconhecimento dos seus, bem como no processo de estabelecer estratégias próprias de vida e suas adversidades" (MAGNINI, 2003, p. 90). Afinal, isto é possível porque a cidade possibilita estabelecer trajetos, circuitos e caminhabilidades.

Barros, Martínez e Viegas (2014) mencionam que a viagem a pé envolve certas condições concebidas na caminhabilidade que estão para além de fatores e indicadores usados para medi-la. Assim, deve-se considerar que o desenho urbano se configura a partir de rede de caminhos, bem como sua densidade e conectividade, aspectos que influenciam e afetam a continuidade e os deslocamentos a pé. 
Retomando ao escrito de Speck (2003), no qual o autor apresenta expressões como tecido urbano e cotidiano de ruas, entendemos que há uma abertura interdisciplinar para o debate sobre as complexidades existentes nas expressões, principalmente no que diz respeito aos grandes centros urbanos. Desse modo, podemos elencar algumas questões, que são pensadas pelas ciências aqui elencadas: Quem utiliza estes espaços? Quais são as dinamicidades que entoam nestes lugares? E quais os fenômenos que interferem em uma caminhabilidade?

De acordo com os expostos e pensando sobre o contexto brasileiro, elencamos alguns fatores que corroboram e encabeçam teoricamente a vivência de uma caminhabilidade a partir de determinados andantes. Antes de tudo, destacamos que a caminhabilidade, diga-se por hora, tranquila e segura é um privilégio social. Afinal, é inevitável não acionarmos debates que envolvem questões de gênero e sexualidades dissidentes. Com isso, destaca-se que tais caminhabilidades para estes dissidentes são interrompidas, desviadas ou brutalmente finalizadas antes do destino final. Isso se deve a uma cultura hegemônica do patriarcado performado pelo machismo, sexismo, e dentre outras formas de opressão em torno do gênero e das sexualidades, posto que as matrizes de opressão sobrepõem de forma diferente as pessoas (LORDE, 2019).

Outro fator que determina a caminhabilidade é a territorialização. Ou seja, a cidade enquanto produção espacial desencadeia dinâmicas complexas a partir de relações e interações sociais, como a demarcação de territórios que fomentam a prática de violência. Com isso, destacamos que existem territórios proeminentes com taxas de violência e criminalização elevados, e que não possuem um planejamento urbano que proporciona mínimas experiências “positivas” com a rua.

Speck (2016), aponta que as cidades devem garantir um ambiente na qual as pessoas desejam estar, em especial as novas gerações que preferem em sua maioria cidades com ruas alegres e movimentas. Assim, a cultura de pedestre pode surgir do processo de caminhabilidade. Desse modo, cria-se um processo de prosperidade local, uma vez que, há uma retenção das novas gerações nas cidades, tornando-as 
economicamente ativas. ${ }^{8}$ Desse modo, “[...] há mais coisas para encorajar as caminhadas do que apenas criar espaços bonitos e seguros" (SPECK, 2016, p. 20).

As cidades e seus caminhantes são perpassados por múltiplas dinâmicas que agenciam os modos como suas práticas e subjetividades são constituídas. E, infelizmente, a violência, em aspecto difuso (BARREIRA, 2013) nos contextos urbanos brasileiros, acaba acionando operações que colocam suas práticas e subjetividades numa linha tênue de subalternidade, de criminalização e negação de si. Se partirmos numa perspectiva interseccional, que veremos mais adiante, os processos de criminalização afetam majoritariamente pessoas negras em espaços periféricos em condição de vulnerabilidade social. Assim, buscaremos brevemente um diálogo transversal sobre questões de gênero, frente a noção da interseccionalidade e da violência urbana, especificamente a violência contra a população LGBTs.

\section{Perspectivas sobre a violência difusa e urbana sob o prisma interseccional}

Para Butler (2018), gênero é um dado normativo que exerce uma função importante (ontológica) no enquadramento da humanidade. Desse modo, o gênero é entendido como um ato performativo que produz e sustenta significados e relações de poder-saber na sociedade moderna. Butler (2018), discorre que o gênero é constituído por conjuntos de atos que dizem estar em conformidade com as normas sociais vigentes, com a produção de sujeitos e subjetividades, àqueles(as) que se rebelam a esta norma, subvertem o gênero e a heterossexualidade compulsória, tidas como "vidas abjetas" (BUTLER, 2020). Nesse sentido, apresentamos a sexualidade como uma importante tecnologia de controle (FOUCAULT, 1998) que historicamente e socialmente tem sustentando as relações de poder-saber que colocam o feminino como subalternizado e em condições de vida mais precarizadas (BUTLER, 2018; SPIVAK, 2010; FACCHINI; CARMO; LIMA, 2020).

\footnotetext{
${ }^{8}$ Destaca-se que a retenção de novas gerações, está correlacionado a saída de jovens norte-americanos de suas cidades natais, em especial as do interior para os grandes centros urbanos. Pode-se apontar que esse processo de (i)migração também se faz presente no Brasil.
} 
Cabe falarmos aqui sobre masculinidades hegemônicas, estas produzidas pelo sistema "cisheteropatriarcal", que sustenta e produz opressões masculinistas (VALENCIA, 2018), seja no âmbito da violência urbana, ou especificamente a LGBTfobia. Machado (2016), destaca a necessidade de explorarmos outros tipos de masculinidades, por exemplo, e que as mesmas possam se colocar em "crise", resultando em questionamentos sobre suas performances. A referida autora, destaca que há uma grande dificuldade em quebrar regras silenciosas de padrões comportamentais expressos em forma de masculinidade, pois normas tão intrínsecas são repetidas constantemente. No quesito de gênero, este entendimento aparece como "forma pela qual as capacidades reprodutivas e as diferenças sexuais dos corpos humanos são trazidas para a prática social e tornadas parte do processo histórico. [...] Através dessa lógica, as masculinidades são corporificadas, sem deixar de ser sociais" (CONNELL, 1995, p. 189).

Tais regras estão presentes em ambientes sociais e políticos onde se deve considerar exigências pautadas em uma coerência total entre um sexo, gênero, desejo/prática unificadas (BUTLER, 2016). Com isso, nos atentamos para a invisibilização dos "corpos feminizados” (LUGONES, 2014) na multidão urbana, é uma chamada a refletir sobre o direito das gays, lésbicas e pessoas trans (que estão fora da masculinidade hegemônica) ao direito à cidade, assim como também problematizamos as violências que sofrem ao caminhar nas ruas e afeta seus cotidianos.

Outra questão que se coloca para o debate é a suposta neutralidade do espaço urbano tendo como pressuposto o atendimento de um sujeito universal, produzido pela colonialidade ainda vigente na sociedade moderna (LUGONES, 2014). Segundo Muxí (2012), defender a universalidade esconde o verdadeiro sujeito de direito, uma vez que tem como critério desenvolver referências do masculino e feminino nos campos privado e público, sendo assim, o espaço doméstico e o controle reprodutivo é definido como natural para o feminino e o sujeito de direito ao espaço público e a liberdade que isso representa é dado a figura do masculino.

Contudo, é importante aqui pontuarmos que esse sujeito de direito, fabricado na colonialidade, é definido de acordo com as sobreposições identitátias e de privilégios sociais, pois, este humano "absuluto" refere-se ao homem, hétero, branco, burguês e europeu (LUGONES, 2014). Desta forma, a universalidade, bem como a neutralidade 
científica são falsas, posto que essas matrizes de poder-saber silenciam, invisibilizam e naturalizam as violências que pessoas fora de suposto universal sofrem (BARROS, et al., 2019).

A discussão da universalidade é central para compreender as dinâmicas de matabilidade para determinadas existências, posto que, havendo um sujeito universal, mascarado como masculino mencionado anteriormente como branco, burguês e eurocentrado, os sujeitos dissidentes estão à mercê da "necropolítica de gênero" (SAGOT, 2013).

A noção de necropolítica de gênero, diz respeito, a produção discursiva e de práticas indutoras de letalidade aos corpos femininos e marginalizados, sobretudo, a construção de um regime de gestão e terror que produz uma "pena" de morte a determinadas mulheres (SAGOT, 2013). Consoante Margareth Sagot, com base em Achille Mbembe acerca do conceito de necropolítica e de Michel Foucault sobre biopolítica, conseguimos traçar uma linha de compreensão para tratarmos de necropolítica de gênero. Contudo, o contexto brasileiro, para além das práticas sexistas, LGBTfóbicas e racistas, amplia-se tal noção teórica-analítica para pensar esse dispositivo de morte em corpos feminizados de LGBTs, especificamente aqueles que se encontram interseccionados ao racismo por estarem mais suscetíveis a necropolítica de gênero. Por tanto, a compreensão da noção de feminizados, se constitui a todos àqueles que não performatizam uma masculinidade hegemônica ou são fabricadas como pertencentes ao “campo feminino", ou seja, estas existências-corpóreas são atravessadas pelo feminino ou pela feminilidade.

Desse modo, na tentativa de compreender as práticas de violência em torno da população LGBTs, o Atlas da Violência em parceria com o Grupo Gay da Bahia e a Associação Nacional de Travesti e Transsexuais (ANTRA), apresentam alguns indicadores tomando como base o número de denúncias de lesão corporal, homicídios e tentativa de homicídio. Com isso, destaca-se que o Brasil é um dos países que mais mata LGBTs no mundo, tendo pico de 88\% entre os anos de 2017 e 2018 (CERQUEIRA, et al., 2020). De modo geral, o número de vidas interrompidas são alarmantes. Dados da população geral, apenas no último Altas da Violência, apontam para 57.956 homicídios, 
isso quer dizer uma taxa de 27,8 mortes por 100 mil habitantes (CERQUEIRA, et al., 2020).

Pontua-se que o avanço neoconservador e neoliberal tem influenciando e consequentemente aumentado o número de violências homofóbicas, lesbofóbicas, bifóbicas e transfóbicas à essa comunidade, bem como valores neopentecostais (SILVA; MIRANDA; SANTOS, 2020), entrelaçado as veias que estruturam o sistema "necroneoliberais" (VALENCIA, 2018), subsidiada por uma compreensão da necropolítica9 (MBEMBE, 2017) de matriz neocolonial no país. Tomamos aqui como exemplo as eleições de 2018, vista como um marco do avanço neoconservador, neoliberal e neofacista no Brasil, desde o início da campanha do atual presidente é notável o aumento de violências LGBTfóbicas no país (BRASIL, 2019). As violências de gênero e a LGBTfóbia nunca deixou de existir no Brasil, contudo, parece que uma tornou-se mais permissiva a "chacotas", discriminação sexual e violências às alteridades após o representante máximo do governo proferir palavras de ódio aos LGBTs, assim como também aos povos originários, quilombolas e étnico-raciais e até mesmo aos nordestinos. A campanha presidencial e tudo que esse governo representa é o fortalecimento da extrema direita, do conservadorismo de base religiosa, sobretudo neopentecostal, e também de um nacionalismo extremista e fascista. São vetores sócio-políticos que acionam a necropolítica de gênero.

Os dados de mortalidade correlacionada pelo discurso de ódio põem em xeque a escassez de indicadores da violência contra pessoas LGBTs, como também nos faz pensar as dinâmicas da opressão difusa nos espaços urbanos de modo estrutural e simbólica, assim deve-se partir uma análise histórica crítica (MARTÍN-BARÓ, 2017). Isto é, a violência não pode ser investigada como um caso isolado ou tomado por uma análise reducionista dos dados estatísticos. A partir de uma dimensão polifónica, multidimensional e multifacetada, a violência difusa "[...] configura claramente o incontrolável e o imponderável” (BARREIRA, 2013, p. 239). Com isso, destaca-se a importância de estudá-la como um fenômeno complexo em um cenário mais amplo.

\footnotetext{
9 Com o avanço do neoliberalismo, segundo Mbembe (2017), o regime biopolítico se atualiza para a necropolítica, em que não se trata mais de gerir como e quem deve viver, mas quem e como deve morrer em larga escala. Trata-se do uso do poder pessoal e político de ditar quem e como determinadas pessoas devem morrer.
} 
Essa configuração atinge, em grande escala, grupos sociais que não se enquadram nas vigências morais culturais e por conjunto de operação de poderes que regem o patriarcado, o machismo, e o sexismo. Assim, se produz uma economia simbólica da violência que intensifica o medo, tornando-se “[...] um sinal de alerta que previne as pessoas acerca de perigos, mas é também um elemento propulsor de ansiedade e ações irracionais" (BARREIRA, 2013, p. 233).

Quando vidas LGBTs são linchadas, decapitadas, carbonizadas, torturadas, a exemplo, o caso de Dandara, ${ }^{10}$ não há comoção pública, mas um processo de criminalização como personificação da abjeção dessas existências (NUNES, 2020). Além do contexto político, os processos de exacerbação da violência urbana, numa configuração difusa, têm corroborado para o avanço de violências contra pessoas LGBTs, denunciando não somente a incapacidade estatal de proteger essas vidas, mas negligenciando-as por não serem contabilizadas em análise de forma crítica. Há, portanto, uma “[...] despreocupação do Estado brasileiro no que tange à mensuração e incidência sobre o fenômeno da violência LGBTfóbica." (CERQUEIRA, et al., 2020, p. 54), assim, inviabilizando a construção de políticas públicas de modo contextual, intersetorial e interseccional.

Destaca-se que ao mesmo tempo que há humanização de corpos que devem ser protegidos, há um processo de desumanização dos que são inteligíveis, logo negligenciados pelo Estado. Trata-se, portanto, de uma condição social e politicamente construída, em que determinados corpos estão em condições mais precárias que outros devido às opressões simultâneas que atravessam suas vidas, sobretudo de pessoas dissidentes de gênero. Nesse sentido, nem todas as vidas são passíveis de proteção

\footnotetext{
${ }^{10}$ Dandara foi brutalmente filmada enquanto era torturada e assassinada em 2017, na cidade de Fortaleza, no Ceará. Seu caso foi emblemático devido à brutalidade com que aconteceu, apesar dos movimentos que lutam por direitos LGBTs viralizaram na internet, anos depois do crime, o que aconteceu segue sendo qualificado como homicídio sem determinação transfóbica. Antes de alcançar essa visibilidade, agentes de segurança pública se esquivavam do caso justificando que levantaria o antecedente criminal de Dandara, de modo a justificar seu assassinato (MARTINELLI, 2019). Essa lógica criminalizante tem sido corriqueira no Ceará em que "envolvidos/as", categoria nativa que enquadra jovens como sujeitos perigosos e atuantes no tráfico de drogas, personifica o/a inimigo/a à ser aniquilado/a e, desse modo, sua morte não ser considerada importante (NUNES, 2020). Recentemente a Câmara Municipal de Fortaleza aprovou um Projeto de Lei que denomina uma rua do bairro Bom Jardim de Dandara Ketley como forma de memorizar a história e vida dela e também de conscientizar as pessoas e incentivar políticas de proteção às pessoas LGBTs (G1 CE, 2020).
} 
(minimização da condição precária) ou de enlutamento (vidas que não são passíveis de luto).

O olhar interseccional, como lente teórica, analítica e política (AKOTIRENE, 2018), viabiliza o entrecruzamento de opressões que tornam o cotidiano de pessoas LGBTs mais vulnerável e precarizado. Nesse sentido, interseccionalidade é:

[...] uma conceituação do problema que busca capturar as consequências estruturais e dinâmicas da interação entre dois ou mais eixos da subordinação. Ela trata especificamente da forma pela qual o racismo, o patriarcalismo, a opressão de classe e outros sistemas discriminatórios criam desigualdades básicas que estruturam as posições relativas de mulheres, raças, etnias, classes e outras (CRENSHAW, 2002, p. 177).

Embora Crenshaw (2002) tenha forjado o conceito de interseccionalidade, destaca-se que anteriormente um grupo de mulheres negras já havia apresentado, não com essa nomenclatura, mas em contexto de luta política dos movimentos sociais abolicionistas, antirracistas e de mulheres negras (LORDE, 2019). Evidenciamos, então, que marcadores sociais e de opressões intercruzam-se, pois a desigualdades de gênero, de classe, de raça, de sexualidade, dentre outros, atuam concomitante nas produções de violências, exclusões e na incapacidade de enlutamento por essas vidas oprimidas e assassinadas.

Nesse sentido, Fátima Lima (2018), em uma pesquisa com mulheres lésbicas a partir de uma ótica interseccional, identifica que os atravessamentos de opressões sociais e identitárias (pobreza, moradoras de favelas, negras e lésbicas), tornam essas mulheres mais expostas as vulnerabilidades produzidas na sociedade neoliberal e sua política de gestão de vida/morte. Cabe ressaltar que não estamos hierarquizando violências, mas visibilizando que estruturalmente, por nossa sociedade ser marcada pela colonialidade de saber, poder e de gênero (QUIJANO, 2005; LUGONES, 2014), há vidas colocadas como mais expostas à violência e menos assegurada pelo poder estatal (BUTLER, 2016; BARROS et al., 2019).

Desse modo, é possível constatar que a interseccionalidade escancara “a condição compartilhada de precariedade conduz não ao reconhecimento recíproco, mas sim a uma exploração específica de populações-alvo, de vidas que não são exatamente vidas, que são consideradas 'destrutíveis'.” (BUTLER, 2016, p.53). Precariedade, está 
ligada ao reconhecimento social, ou as representações sociais que foram apontadas ao longo deste escrito (BUTLER, 2019).

Esses processos de precarização e desigualdade da vida, requer que questões de gênero e sexualidade sejam transversalizadas com questões socioeconômicas, territoriais e raciais. De modo que, políticas públicas devem se atentar para essa inseparabilidade interseccional, de forma que o Estado se responsabilize por essas mortes e desenvolva e potencialize redes de combate, proteção e prevenção às pessoas LGBTs. Dialogando com Ribeiro (2018), a falta do olhar interseccional ao pensar políticas públicas de enfrentamento da violência, impossibilita compreender as complexidades da sociedade contemporânea marcadas pela genderização, racialização, periferização e LGBTfobia.

\section{Notas sobre a caminhabilidade: diversidade sexual e de gênero no Brasil}

A violência se evidencia num emaranhado acúmulo de conflitos pautado, não de modo restrito, mas paradoxal, na negação, subordinação e no extermínio do outro. A violência humana assume "[...] um caráter particular, individual [e coletivo] ou de premeditação" (COSTA, 1997, p. 282), apresentando-se muitas vezes de modo sistemático. Para o caso brasileiro é salutar transcrever as palavras de Wagner Cabral em entrevista à Profá. Salviana Sousa da Universidade Federal do Maranhão, quando discorre sobre os traços históricos da cultura da violência no Brasil:

Em virtude do processo de (de)formação da sociedade nacional, caracterizado
pelo genocídio indígena, pela escravização do negro africano, pelo latifúndio
exportador e pelo patriarcalismo, o Brasil sempre foi marcado historicamente
pelo predomínio de uma cultura da violência. Mesmo que tal processo tenha
sido mascarado pela invenção de mitos fundadores que enfatizavam ideias
como a (suposta) harmonia entre colonizador e colonizado, a (falsa)
democracia racial, uma (enganosa) história de um povo bom, pacífico e ordeiro,
em comunhão com uma terra abençoada pela inexistência de guerras, do
brasileiro como um homem cordial (no sentido restrito de povo hospitaleiro,
alegre e gentil, mas esquecendo o componente de forte passionalidade dessa
ideia-imagem, ressaltado por Sérgio Buarque de Holanda) (SOUSA, 2o18, p.
945).

Dessa forma observa-se um processo de acobertamento/apagamento das violências do passado e do presente, ou seja, não se fala, não se debate as violências do 
cotidiano nos espaços institucionais, o que mantém os preconceitos contra minorias. As pessoas e populações dissidentes sexuais e de gênero, são alvos constante da violência urbana, como pode ser visto na obra de Melo (2018) ao apresentar os dados oficiais dos Relatórios de Violência Homofóbica no Brasil (2011, 2012 e 2013) organizado pela Secretaria de Direitos Humanos da Presidência da República, e os dados anuais do Grupo Gay da Bahia (GGB). O Brasil é um país hostil para se experienciar uma sexualidade que não corresponda uma inteligibilidade do gênero, ou seja, que "[...] instituem e mantêm relações de coerência entre sexo, gênero, prática sexual e desejo" que tem por base a heteronormatividade (BUTLER, 2015, p. 43).

Melo (2018) lembra que no Brasil, os Movimentos Sociais de Lésbicas, Gays, Bissexuais, Travestis, Transexuais e Transgêneros, popularmente conhecido sobre a sigla LGBTs, em um primeiro momento, em especial nos anos de 1980, voltam suas lutas sociais em torno da epidemia de AIDS. Mas posteriormente voltou-se para o combate à homofobia. Vale ressaltar que o cenário social não apenas assolado pela epidemia, consecutivamente fez enfraquecer e diminuir os movimentos de resistências LGBTs, mas por outro lado, emergiu como uma questão pública, midiática e sanitária, o emblema da homossexualidade no Brasil, e com isso, “[...] mostrando que, além do combate à epidemia de AIDS, era necessário combater a epidemia da violência, da discriminação, do preconceito e a pior de todas as formas de homofobia: os homicídios motivados pelo ódio a homossexuais" (MELO, 2018, p. 16).

Trevisan (2018, p. 493) aponta que no Brasil “[...] das primeiras décadas do século XXI, políticas relacionadas à raça, gênero e sexualidade tomaram um impulso comparável ao das grandes guinadas, no anseio pela democratização social mais justa. Nem por isso seria adequado dizer que tais lutas chegaram à conquista do Paraíso", afinal, como pode ser visto, as conquistas de ordem normativa foram alcançadas pelas vias do Poder Judiciário, enquanto que os Poderes Legislativo e Executivo (com exceção do Governo Lula) se mostram alheios as pessoas e populações LGBTs, assim, para muitos dissidentes sexuais e de gênero a rua ainda é sinônimo do medo.

É a partir desse contexto histórico e social permeados por antagonismos no que diz respeito às lutas e anseios das pessoas e populações LGBTs no contexto brasileiro, que, se compreende uma interface entre as desigualdades operantes na diversidade no 
tocante de uma caminhabilidade "segura" na cidade, sobretudo, presente nos corpos que maximizam os estereótipos do preconceito, da indiferença e de uma feminilidade performativa (ORTON, 2017).

Não obstante, destacamos notícias veiculadas em jornais e sites de grande repercussão nacional que exemplificam nossa discussão sobre o espaço público, a saber: 1) Casal gay é espancado com pá após abraço e alega homofobia: 'bichinhas';"112) Travesti Dandara foi apedrejada e morta a tiros no Ceará,12 3) Pai e filho são confundidos com casal gay e agredidos por grupo em São João da Boa Vista, SP;13 4) Acusado de atropelar e matar vendedor de tapiocas é condenado a medidas cautelares - Victor de Carvalho Alves, que atropelou um motociclista enquanto tentava atingir uma travesti, em abril, terá que usar tornozeleira eletrônica até o final do processo. ${ }^{14}$ Como pode se observar, o espaço público não se apresenta como um lugar seguro para os dissidentes sexuais e de gênero.

Corroborando com a reflexão de que a violência letal recrudesce a via pública como não segura, Góis e Soliva (2017) aponta que somado a performatividade do corpo, são comumente desencadeadores de ódio e intolerância expressões de afetos e inconcordância com as posições individuais de mudança de sexo, na grande maioria das queixas das vítimas. Esse enclausuramento das condições singulares das pessoas tende a produzir o medo social e aspectos de constrangimento nas interações e relações interpessoais, e que estão tão legitimadas nas violências físicas, psicológicas e morais. Conforme Góis e Soliva (2017), “[...] a porta da boite [boate], a própria boite [boate], assim como outros estabelecimentos comerciais, mesmo que de frequência marcadamente gay, são locais em que o preconceito se expressa por meio de diferentes formas de violência” (GÓIS; SOLIVA, 2017, p. 13).

\footnotetext{
${ }^{11}$ Disponível em: http://g1.globo.com/sp/sao-carlos-regiao/noticia/2017/o3/casal-gay-e-espancado-compa-apos-abraco-e-alega-homofobia-bichinhas.html - Acesso em: 10. Mar. 2020.

${ }^{12}$ Disponível em: http://g1.globo.com/ceara/noticia/2017/o3/apos-agressao-dandara-foi-morta-com-tirodiz-secretario-andre-costa.html - Acesso em: 10. Mar. 2020.

13 Disponível em: https://oglobo.globo.com/brasil/pai-filho-sao-confundidos-com-casal-gay-agredidospor-grupo-em-sao-joao-da-boa-vista-sp-2714592 - Acesso em: 10. Mar. 2020.

14 Disponível em: https://diariodonordeste.verdesmares.com.br/editorias/seguranca/online/acusado-deatropelar-e-matar-vendedor-de-tapiocas-e-condenado-a-medidas-cautelares-1.1774396 - Acesso em: 10. Mar. 2020.
} 
É nesse ínterim que buscamos um diálogo com a Teoria da Caminhabilidade de Jeff Speck (2016), que tem sua centralidade nos desenhos urbanos de deslocamento dos sujeitos que vivem em um território. Faz-se necessário apontar que a Teoria da Caminhabilidade é oriunda da arquitetura e urbanismo e têm seus fins no desenvolvimento e planejamento urbano, mas também se abre para uma reflexão socioantropológica sobre o espaço urbano e a rua. Assim, dialogamos sobre gênero e sexualidade no Brasil e os processos de caminhabilidade que envolvem desde o planejamento da segurança física dos pedestres em sua caminhada, até o momento que se faz uma travessia na rua, ou quando se está andando ou descansando na calçada. Para além dessas questões, e conforme foi discutido ao longo do artigo, a caminhabilidade também é atravessada por questões subjetivas, que implicam diretamente no modo desse sujeito caminhar sobre as ruas da cidade.

A Teoria da Caminhabilidade, pensada a partir dos contextos brasileiros, nos instiga a refletir para além dos procedimentos técnicos que estão implicados para uma boa caminhada (largura das calçadas e ruas, locais de estacionamento, arborização, etc.), incluímos então as questões de gênero e sexualidade como um fator que pode dificultar a caminhada em espaços urbanos mais populares, implicando dizer que, planejamento urbano deve estar relacionado aos aspectos socioculturais dos caminhantes.

\section{Considerações finais}

À guisa de uma conclusão, buscamos com este texto não propor um fechamento da temática ou de uma análise fatalista sobre a caminhabilidade dos corpos LGBTs. Nossas análises apontam que a caminhabilidade segura dos corpos dissidentes de gênero e sexualidade são recrudescidas pela violência urbana de gênero e de intolerância às dissidências sexuais e de gênero. Isso implica dizer que a violência letal é intensa e, se mostra ainda não representativa da população LGBTs no Brasil, uma vez que as políticas públicas não possuem um monitoramento efetivo de dados com esse segmento populacional ou mesmo políticas preventivas eficazes, e diversas vezes, os dados obtidos partem de iniciativas não-governamentais e de movimentos sociais. 
O histórico de nossa herança colonial se perfaz nas violências que acometem os corpos feminizados. Vimos que quando analisamos o cenário social sob o prisma interseccional, a violência urbana se intensifica nos corpos negros, pobres, marginalizados dos territórios periféricos, corpos abjetos e não passíveis de luto. Atrelado ao discurso de ódio e de intolerância, seja digerido pelas questões morais, religiosas, patriarcais, machistas e fascistas, são grandes fatores que atormentam ou bloqueiam a caminhabilidade da população LGBTs. Os efeitos repercutem na produção de uma invisibilidade social que não opera somente na caminhabilidade da via pública, mas que é presente também nos espaços institucionais e da coletividade cotidiana.

Sabemos que a discussão do tema da caminhabilidade não se esgota somente com a nossa reflexão proposta, uma vez que, a própria teoria se utiliza de outras áreas do saber, como arquitetura, paisagismo, história social e dentre outras para explorar o potencial de "caminhada segura". Empreendemos um olhar lançado sobre a violência urbana e difusa, acirrada pela necropolítica de gênero, como um vetor de análise dos impactos que atravessam a população LGBTs e suas liberdade de transladar, performatizar e viver livremente pela cidade com seus desejos e singularidades. Portanto, suscitamos que estudos sobre as singularizações, produções de resistências e alianças sociais possam produzir desdobramentos de estudos sobre a caminhabilidade segura dos corpos dissidentes de gênero e sexualidade.

\section{Referências}

AGIER, M. Do direito à cidade ao fazer cidade: o antropólogo, a margem e o centro. Maná, Rio de Janeiro, v. 21, n. 3, p. 483-498, 2015.

AKOTIRENE, C. O que é interseccionalidade? (Feminismos Plurais - Coordenação Djamila Ribeiro). Belo Horizonte: Letramento: Justificando, 2018.

ALVES, G. A. (2012). A mobilidade/imobilidade na produção do espaço metropolitano. In: CARLOS, A. F. A., SOUZA, M. L. \& SPOSITO, M. E. B. (Org.) A produção do espaço urbano: agentes e processos, escalas e desafios. São Paulo: Contexto.

BARREIRA, C. Violência difusa, medo e insegurança: as marcas recentes da crueldade. Revista Brasileira de Sociologia, v. 1, n. 1, 2013. 
BARROS, A. P. B. G.; MARTÍNEZ, L. M. G. \& VIEGAS, J. M. A caminhabilidade sob a ótica das pessoas: o que promove e o que inibe o deslocamento a pé?, Revista Ur. Barcelona, n. 8, 2015 .

BARROS, J. P. P. et al., Criminalização, extermínio e encarceramento: expressões necropolíticas no Ceará. Revista Psicologia Política, v. 19, n. 46, p. 475-488, 2019.

BRASIL. Violência contra LGBTs+ nos contextos eleitoral e pós-eleitoral. Gênero e número. 2019. $\quad$ Disponível em <http://violencialgbt.com.br/dados/190321_relatorio_LGBT_V1.pdf> Acesso em: 5 set. 2020 .

BUTLER, J. Corpos que importam. São Paulo: N-1. 2020.

BUTLER, J. Problemas de gênero: feminismo e subversão da identidade. 16 a $^{\mathbf{a}}$ ed. Civilização Brasileira: Rio de Janeiro, 2018.

BUTLER, J. Quadros de guerra: quando a vida é passível de luto? Rio de Janeiro: Civilização Brasileira. 2016.

BUTLER, J. Vida precária: os poderes do luto e da violência. Belo Horizonte: Autêntica Editora. 2019.

CARNEIRO, S. Racismo, Sexismo e desigualdade no Brasil.São Paulo: Selo Negro. 2011. (Coleção Consciência em debate).

CERQUEIRA, D. et al. Atlas da violência 2019. Rio de Janeiro: Instituto de Pesquisa Econômica Aplicada; Fórum de Segurança Pública, 2018. Disponível em: https://www.ipea.gov.br/atlasviolencia/arquivos/downloads/6537-atlas2019.pdf. Acesso em: 15. jun. 2020.

COLLING, L. A. Que os outros sejam o normal: tensões entre movimento LGBT e ativismo queer. Salvador: Edufba, 2015.

CONNELL, R. Políticas da masculinidade. Educação \& Realidade. v. 20, n. 2, p. 185206, 1995.

CONNELL, R. Questões de gênero e justiça social. Século XXI, Revista de Ciências Sociais, v.4, no 2, p.11-48, 2014.

COSTA, C. Sociologia: introdução à ciência da sociedade. São Paulo: Moderna, 1997.

CRENSHAW, K. Documento para o encontro de especialistas em aspectos da discriminação racial relativos ao gênero. Estudos Feministas, Santa Catarina, v. 10, n. 1, p.171-188. 2002. 
FACCHINI, R.; CARMO, I. N.; LIMA, S. P. Movimentos Feminista, Negro e LGBTI no Brasil: sujeitos, teias e enquadramentos. Educ. Soc., Campinas, v. 41, 2020.

FOUCAULT, M. História da sexualidade I: a vontade do saber. Rio de Janeiro: Edições Graal, 1998.

Gı CE. Rua de Fortaleza homenageia Dandara dos Santos e será a $1^{\mathrm{a}}$ do Ceará com nome de uma travesti. G1 CE. 2020. Disponível em: <https://g1.globo.com/ce/ceara/noticia/2020/12/o9/rua-de-fortaleza-sera-a-primeirado-estado-a-ter-nome-de-travesti.ghtml> Acesso em: $12 \mathrm{dez} .2020$.

GAMSON, J. As sexualidades, a teoria queer e a pesquisa qualitativa. In: DENZIN, N. K. \& LINCOLN, Y. S. (Org.) O planejamento da pesquisa qualitativa: teorias e abordagens. Porto Alegre: Artmed. 2006

GHIDINI, R. A caminhabilidade: medida urbana sustentável. Revista dos Transportes Públicos, 33, 21-33. 2010.

GIL, A. C. Métodos e técnicas de pesquisa social. São Paulo: Atlas. 2009.

GÓIS, J. B. H.; SOLIVA, T. B. A rua e o medo: algumas considerações sobre a violência contra jovens homossexuais em espaços públicos. Anais do XVI Encontro Nacional de Estudos Populacionais, p. 1-15, 2019.

GONZALEZ, L. Racismo e sexismo na cultura brasileira. Revista Ciências Sociais Hoje, Anpocs, p. 223-244. 1984.

GRUPO GAY DA BAHIA. Mortes violentas de LGBT+ no Brasil 2019. Relatório do Grupo Gay da Bahia. 2020. Disponível em: <https://grupogaydabahia.com.br/relatorios-anuais-de-morte-de-lgbti/> Acesso em: 05 set 2020 .

JOAS, H.; KNÖBL, W. Teoria Sociais Feministas. In: Teoria Social: vinte lições introdutórias. Petrópolis, RJ: Vozes, 2017. p. 436-493.

LIMA, F. Sobre dores, saudade e (re)existências. Cadernos de gêneros e diversidade, Dossiê: Raça, interseccionalidade e violência: corpos e processos de subjetivação em mulheres negras e lésbicas, v. 4, n. 2, p. 66-82, 2018.

LORDE, A. Irmã outsider. Belo Horizonte: Autêntica Editora, 2019.

LUGONES, M. Colonialidad y género: hacia un feminismo descolonial. In: MIGNOLO, W. et al. Género y descolonialidad. Ciudad Autónoma de Buenos Aires: Del Signo, 2014, p. 13-42. 
MACHADO. B. F. Estudos de masculinidades: a crise masculina, a masculinidade hegemônica e a paternidade em Onde estão os ovos?, de Fabrício Carpinejar. Mosaico, v.7, n. 11, p. 50-63. 2016.

MAGNANI, J. G. C. A antropologia urbana e os desafios da metrópole. Tempo Social, v. 15 , n. 1, p. 81-95, 2003.

MARTÍN-BARÓ, I. Da guerra suja à guerra psicológica: o caso de El Salvador. In: I. Martín-Baró, Crítica e liber-tação na Psicologia: Estudos psicossociais. Petrópolis, RJ: Vozes. 2017, p. 271-285.

MARTINELLI, A. Caso Dandara ainda espera respostas do poder público dois anos após sua morte brutal. Huffpostbrasil, 16 fev. 2019. Acesso em: 25 dez. de 2019. Disponível em: $\quad<$ https://www.huffpostbrasil.com/entry/dandara-dois-anos-travestiassassinato_br_5c67742ee4bo1757c36bb716>.

MBEMBE, A. Políticas de inimizade. Lisboa: Antígona, 2017.

MELO, M. A. S. Crimes de ódio e violência contra LGBT no Brasil: um estudo a partir do nordeste brasileiro. São Paulo: Embu das Artes. 2018.

NASCIMENTO, A. O genocídio do negro brasileiro: processo de um racismo mascarado. São Paulo: Perspectiva, 2016.

NASCIMENTO, R. F. A.; LUCENA, I.; GOMES FILHO, A. S. "O bairro é dividido em dois, professores! O João é a parte rica, e o Cabral é a parte pobre onde fica a favelinha.”. In: MELO, M. A. S.; GOMES FILHO, A. S.; LOBO, C. E. D. Saberes e Dizeres no Cariri Cearense: gênero, religiosidade, africanidades e segurança pública. Curitiba: CRV, 2016.

NUNES, L. F. "Quando vi, tava envolvida": atravessamentos da violência urbana nas trajetórias de adolescentes privadas de liberdade. Dissertação. (Mestrado em psicologia) - Programa de Pós-Graduação em Psicologia, Universidade Federal do Ceará, Fortaleza. 2020.

ORTON, N. El. (Des)igualdade de gênero e a (i)mobilidade urbana contemporânea: uma visão goffmaniana. RUA, v. 23, n. 2, p. 243-266, 2017.

PERES, M. C. C.; SOARES, S. F.; DIAS, M. C. Dossiê sobre lesbocídio no Brasil: de 2014 até 2017. Rio de Janeiro: Livros ilimitados. 2018.

PRADO, M. A. M., \& MACHADO, F. V. Preconceito contra homossexualidades: a hierarquia da invisibilidade. São Paulo: Cortez. 2012.

RIBEIRO, D. Quem tem medo de feminismo negro? São Paulo: Companhia das Letras, 2018. 
SAGOT, M. El feminicídio como necropolítica en Centroamérica. Labrys, éstudes féministes, 2013. Disponível em: <https://www.labrys.net.br/labrys24/feminicide/monserat.htm>. Acesso em: 9 agos. 2018.

SERPA, A. Lugar e centralidade em um contexto metropolitano. In: CARLOS, A. F. A., SOUZA, M. L. \& SPOSITO, M. E. B. (Org.). A produção do espaço urbano: agentes e processos, escalas e desafios. São Paulo: Contexto. 2012.

SILVA, D. S. N.; MIRANDA, M. H. G.; SANTOS, M. C. G. Homofobia e interseccionalidade: sentidos condensados a partir de uma pesquisa bibliográfica. Revista interritórios, v. 6, n. 10, p. 200-224, 2020.

SOLIVA, T. B. The street and fear:reflections on the violence experienced by Young gay men in public spaces. Revista Latino-americana de Geografia e Gênero, v. 2, n. 1, p. 122-132, 2011.

SOUSA, S. M. P. S. Sobre a questão da violência: uma entrevista especial com Wagner Cabral. Revista de Políticas Públicas, v. 22, n. 2, p. 945-96o, 2018.

SPECK, J. Cidade caminhável. São Paulo: Perspectiva. 2016.

SPIVAK, G. C. Pode o subalterno falar? Belo Horizonte: Editora da UFMG, 2010.

TREVISAN, J. S. Devassos no paraíso: a homossexualidade no Brasil, da colônia à atualidade. Rio de Janeiro: Objetiva. 2018.

VALENCIA, S. El transfeminismo no es un generismo. Pléyade, v. 1, n. 22, p. 27-43, jul., 2018.

VERGUEIRO, V. Por inflexões decoloniais de corpos e identidades de gênero inconformes: uma análise autoetnográfica da cisgeneridade como normatividade. 2015. 244 f. Dissertação (Mestrado). Programa Multidisciplinar de Pós-Graduação em Cultura e Sociedade. Universidade Federal da Bahia (UFBA), Bahia, Salvador, 2015. 